\title{
EM TORNO DO PROGNOSTICO ATUAL DAS PARAFRENIAS
}

\author{
VIRGflio CAMARgo PACHECO * \\ F. MARIZ DE OLIVEIRA NETO **
}

Falar sôbre a evolução das idéias que precederam os trabalhos de Kraepelin, dos quais resultou o conceito das parafrenias, separadas após longas hesitações da demência prococe, é recordar, em largos traços, quase tôda a história da psiquiatria, finalidade que não visamos. Apenas queremos frisar, para mais fácil compreensão do que iremos expor, que não raros os especialistas que ainda hoje empregam indiferente. mente as denominações parafrenias e delirio alucinatório crônico. Julgamos que, atualmente, os conceitos clínicos de delírio alucinatório crônico segundo Gilbert-Ballet, e parafrenias, de Kraepelin, não são perfeitamerte superponivess.

A classificação dos distúrbios psíquicos tentada por Pinel mania, melancolia, demencia, idiotismo -- denunciava já preocupação de separar os estados agudos dos crônicos. Esquirol não tardou em dividir essa noção de melancolia em duas partes: a primeira constituiria a melancolia pròpriamente dita ou lipemania, e a segunda seria o material com que se iria edificar o célebre conceito das nonomanias que, não sendo aceito integralmente pela maior parte dos alienistas irancêses que sucederam a Esquirol, levantou uma onda de protestos fecunda em suas conseqüências. Logo se desenhou uma reação no sentido de separar, dessas monomanias, um grupo de delírios crônicos adstrito $_{j}$ a perturbações gerais evolutivas do psiquismo. Esse seria o sentido do memorável trabaiho de Lasègue - Do Delírio de Persee o de Morel sôbre certos delirantes hereditários que se apresentavarn como perseguidos raciocinantes, análogos aos querelantes, da escola alemã. Finalmente, Magnan lançou derradeiro protesto sôbre o perigo da extensão demasiada da noção das monomanias, com a noção de delírio crônico de evolução sistemática, em oposição aos delírios sistematizados dos degenerados. Gilbert-Ballet, ao criticar essa concepção de Magnan, criou o conceito de delírio alucinatório crônico, englobado no capítulo geral das psicoses alucinatórias crônicas.

\footnotetext{
Trabalho apresentado no "Centro de Fistudos Franco da Rocha", em 23 de de julbo de 1947.

- Diretor do Sanatório Bela Vista.

* Assistente-psiquiatra no Sanatório Bela Vista.
} 
A noção de psicose alucinatória crônica, tal camo a concebeu Ballet em 1911, permaneceu intangível na psiquiatria francêsa até 1921, sendo adotada sem restrições por Sérieux e Capgras. Sòmente Claude e os de sua escola ousaram voltar-se contra ela. Para Claude, esta expressão poderia ser aceita no período de edificação psiquiátrica em que foi lançada, pois, nessa acasião, tratava-se de agrupar uma série de perturbações mentais nas quais os autores procuravam pôr em relêvo o papel do que êles chamavam alucinação. Infelizmente, o estudo das observaçõeõs mostrou que, em muitos casos etiquetados sob êste têrmo, não havia verdadeiramente alucinações, mas sim una espécie de fenômenos delirantes tomando a aparência de ações vindas do exierior: "Eu percebo vozes quando quero"; "Isto se passa em minha cabeça", "esta voz me fala em pensamento"; "eu não posso ler"; "há alguém que lê antes de mim". Tais exemplos dizem bem das dificuldades em diferençar exatamente êsses mecanismos psicopatológicos. Essa a razão imperiosa que levou Claude a perguntar se não seria melhor, antes de usar o têrmo alucinação, procurar apoiar-se sobretudo na natureza do delírio e, em segundo lugar, sôbre sua origem. Sem dúvida nenhuma, valendo-nos do estoque de observações classificadas provisòriamente sob a designação de "psicose alucinatória crônica;, e, sob o impulso dos trabalhos de Kraepelin, das aplicações das descobertas psicanalíticas à clínica psiquiátrica, temos atualmente tendência a criar grupos mórbidos caraterizados pela estrutura dos delírios e pelo fundo mental dos indivíduos observados e não pelo aparecimento precário de alucinações, frequentemente de separação difícil de outros mecanismos psicopatológicos. Tal o motivo que justifica plenamente a afirmação de Claude, quando diz que o estudo da estrutura psicopatológica terá que dar, em psiquiatria, os mesmos magníficos resultados que o método anátomo-clínico deu em neurologia.

Essas as razões pelas quais fizemos esta digressão no sentido de justificar nossa atitude, não empregando a expressão "psicose alucinatória crônica" como idêntica à de parafrenias, pois julgamos que a primeira delas vem perdendo os foros de cidade.

Ao mesmo tempo que, em França, a evolução de idéias originou o conceito de "psicose alucinatória crônica", um trabalho idêntico processou-se na Alemanha desde 1863, resultando no concêito das parafrenias. Com efeito, for nessa época que Kahlbaum substituiu o termo Verrücktheit pelo de paranóia. Mas o vocábulo paranóia, longe de ter a significação atuai, serviu inicialmente para designar tôda a espécie de delírio com idêntico decurso: fases melancólica, maníaca, de delírio parcial, de delírio generalizado, demencial. Os domínios da paranóia eram inicialmente tão vastos que, como nos diz 
Frey, "um adolescente com delírio desconexo podia ser tomado como um antigo paranóico do qual o sistema delirante se tivesse dissociado".

O conceito de paranóia foi sendo restringido. Dêle se retiraram os delírios primários como opostos às psicoses onde as perturbações afetivas tomavam o primeiro lugar (mania e melancolia). Mesmo assim, seus domínios continuavam vastíssimos, pois, sob esta rubrica se etiquetava, na Alemanha, cêrca de $70 \%$ dos pacientes internados por distúrbios psíquicos. Foi nessa ocasião que Kraepelin criou, numa de suas concepções sintéticas, o grupo da demência precoce, onde colocou a hebefrenia de Kahlbaum, a catatonia e as mútiplas formas que, tendo sistematização imperfeita, evolu:am com rapidez para um grande rebaixamento mental. Êsses quadros mal sistematizados vieram constituir as formas paranóides da demência precoce. A demência precoce paranóide abrange, assim, na concepção kraepeliniana, as formas constituídas por delírios crônicos acidentais com dissociação mais ou menos generalizada da personalidade (Zeerfall der Persönlichkeit).

Entre os dementes precoces paranóides e os portadores de paranóia existia um espaço vasio que devia ser ocupado pelos pacientes que, sem apresentarem um sistema delirante bem organizado como os delírios interpretativos dos paranóides, mostravam um delírio que, influenciado pelos distúrbios sensitivos, eram diferentes do quadro da demência precoce paranóide. Os temas delirantes eram melhor organizados, a evolução' para a demência era, na maioria dos casos, tardia ou mesmo ausente, além de que, tais indivíduos, àparte os assuntos condizentes com os temas delirantes, guardavam apreciável unidade de ação, sendo tresmo capazes de ventilar assuntos de ordem geral de maneira bastante aceitável.

Segundo faz notar Henry Nodet, a definição das parafrenias não está senão virtualmente contida no tratado de Kraepelin. Este autor teve grande relutância em separar as parafrenias da demência precoce, o que é provado por estarem as duas entidades nosológicas estudadas num mesmo capítulo. Frey acredita ter o mestre de Munich estabelecido sómente diferença de grau entre as duas entidades, e pensa poder definir as parafrenias, segundo Kraepelin, como delírios sistematizados crônicos acidentais, com dissociação limitada. O que não resta dúvida é que, ao contrário do conceito de psicose alucinatória crônica de Gilbert-Ballet, onde a alucinação ocupava o primeiro plano, nas parafrenias, o modo de aparecinento dos sintomas, o decurso e a determinaçz̃o foram levados em grande conta, embora os distúrbios sensoriais não deixassem de ser apreciados.

A digressão que fisemos, não justificando o título do trabalho, tem o mérito de lembrar as discondâncias sôbre a limitação da noção de parafrenias e mostrar a possibilidade de prognóstico completamente 
diferente nos casos de parafrenia orgânica e naqueles nos quais a moléstia tem motivos psicogenéticos. É o que tentaremos provar com casos pessoais.

Admitindo que as parafrenias constituem uma entidade clínica bem delimitada, tendo, contudo, pontos de contacto com a constelação esquizafrênica, julgamos ser razoável tentarmos aplicar o critério de Claude, com referência ao conceito das esquizof renias. Este autor, no Congresso de Genebra, chamou a atenção dos que reuniram, em um mesmo grupo, estados demenciais de origem evidentemente orgânica com estados esquizofrênicos cujo componente psicógeno seria predominante. Isso porque se, clinicamente, êsses quadros esquizofrênicos caraterizam-se por defeito da adaptação ao real, são, no entanto, distintos por vários pontos: num, o componente psicógeno é escasso ou nulo - demência com destruição da inteligência e da afetividade, obrigando o paciente a refugiar-se no narcisismo mais primitivo, como aquêle caraterizado pelo autoerotismo, estado de regressão em que a personalidade combalida, por um processo orgânico severo, encontra uma segurança noutro, a origem psicogenética, embora favorecida por predișnsiçijes individuais, desempenha papel essencial. Neste último caso, havendo certamente dissociação da atividade intelectual, da afetividade, da associação de idéias, o material do pensamento está deslocado, fora de foco, mas não desaparecido. O narcisimo secundário, embora presente, não obriga a personalidade a uma regressão tão acentuada, como no primeiro caso. Os complexos afetivos, os conflitos, as aspirações frustadas, desempenham influência decisiva, dando lugar a uma espécie de reação - a reação esquizofrênica - que pode ser durável, desde que tais motivações psicogenéticas não consigam ser afastadas. Ao contrário das esquizofrenias nítidamente orgânicas em que há liberação das atividades inferiores, segundo a fórmula jacksoniana, os indivíduos portadores de reação esquizofrênica podem refugiar-se em uma compensação ideo-afetiva. Claude vale-se do têrmo esquizose para designar êstes tipos de reação esquizofrênica.

Baseados nos casos que observamos, julgamos poder aplicar, com freqüência, as idéias de Claude às parafrenias. Se existem quadros parafrênicos nítidamente dependentes de um processo orgânico que pode ser incriminado como principal, também há casos em que a gênese psicogenética é indiscutível. Propomos que, um vez verificada a origem psicogenética de um quadro parafrênico seja usada a expressão parafrenose, que caraterizaria um quadro parafrênico de situação ou reativo, evidentemente menos grave, de melhor prognóstico que a parafrenia-moléstia. A evolução da moléstia, com a regressão total da sintomatologia mórbida, desde que os recalques, conflitos e frustaçóes sejam neutralizados, serviria para provar a gênese psicogenética. 
E óbvio notar que, entre os casos nitidamente orgânicos e os psicogenéticos puros, há casos intermediários em que os mecanismos etiológicos misturam-se em proporções impossíveis de serem balanceadas com exatidão.

Para que possamos fazer o diagnóstico diferencial entre parafrenia vera e o que chamamos parafrenose, devemos levar em conta a apresentação do paciente diante do especialista. Os portadores de parafrenia orgânica mostrando-se desde o início sombrios e reticentes, ao passo que os individuos com reação parafrênica de origem psicógena, são abertos, confiantes, sem resquício de hostilidade no início da psicose. E preciso, além disso, fazermos a reconstrução cuidadosa da personalidade pré-psicótica do paciente e, mais que tudo, valermo-nos da noção de compreensibilidade $\mathrm{e}$ incompreensibilidade da sintomatologia apresentada, noção essa muito bem estudada pela escola fenomenclógica. Sabemos, a êsse respeito, que os temas delirantes e as reações mórbidas dos portadores de distúrbios psiquicos ligados a un processo orgânico, são muito menos compreensíveis, de muito mais difícil interpretação afetiva, do que quando o romance delirante está estribado em um fator psicogenético.

Um processo orgânico provoca, segundo Bleuler, distúrbios primários, fundamentais, que soem traduzir-se por sintomatologia deficitária, improdutiva. A essa sintomatologia vem juntar-se outra, secundária, produtiva e reativa, que traduz o protesto da persnnalidade contra o ataque a elementos nobres do sistema nervoso. Esta parte reativa, psicogenética, será tanto menos compreensível, caótica e desordenada, quanto maior fôr a lesão orgânica, como acontece, por exemplo, nos delírios desconexos, completamente absurdos, dos indivíduos portadores de meningoencefalite difusa já muito evoluída.

Aplicando aos portadores de um quadro clínico parafrênico, essa noção da compreensibilidade dos temas delirantes, poderemos chegar a concluir se se trata de uma parafrenia ôrganica, de uma parafreniamoléstia, de prognóstico sempre sombrio, ou se estamos diante de uma forma parafrênica reativa ou de situação, de evidente origem psicógena e, portanto, de muito melhor prognóstico. Nesta última hipótese, depois de uma interpretação afetiva do $\cdots$

observado, poderemos sintonizar nosso Eu contínuo com seu $\mathrm{Eu}$, para nós discontínuo, para que, afinal, estejamos em condições de compreender, em tôda plenitude, seus problemas sociobiopsíquicos.

$E$ óbvio que, para estarmos em condições de compreender as idéias delirantes do portador de uma reação parafrênica de origem psicógena, precisamos encarar o organismo como um todo, em que as funções, em vez de serem 1soladas, são estruturadas em sistemas, como faz a Gestalt-Psychologie. Precisamos ainda não nos esquecer que os sin- 
tomas, tanto psíquicos como somáticos, podem simbolizar a defêsa do indivíduo que, pela psicose, procura escapar às situações julgadas insolúveis. A medida que formos estudando mais detidamente tais pacientes, iremos vendo que há sempre um sentido oculto na aparente incoerência dos sintomas. Nestes caso's, os fenômenos alucinatórios podem, muitas vezes, ser tomados como personalizações do super-ego e tem um conteúdo afetivo constituído de recalcamentos, frustações e discretas regressões, em que estados intersexuais dissimulados, a par de marcante desnível entre as apetências instintivas e o poder de realização, desempenham papel de grande relêvo. Estes casos esquematizam bem o mecanismo de projeção que Hesnard descreveu com o nome de altruização, e Pichon, com o de projeção. Aqui os pacientes tomam as impressões internas como vindas de fora, deflagrando-se então tendências profundas, enèrgicamente recalcadas que, irrompendo na consciência de maneira abrupta, fazem tais indivíduos não as reconhecerem como suas; daí a tendência de atribuírem a outrem a responsabilidade dêsse estado de cousas.

Uma vez chegados a êste ponto, só nos resta intervir com uma terapêutica ativa - psicoterapia mais ou menos demorada, psicanálise, narcoanálise - para estarmos em condições de resolver os conflitos internos de tais pacientes. Preliminarmente, costumamos submeter os portadores de tais quadros psicóticos a uma série de crises convulsoterápicas, associadas ou não à insulinoterapia, como manobra de "amaciamento"; dêsse modo, quebramos-lhes a fachada sintomática mais grosseira, esbatendo ao mesmo tempo o narcisismo secundário que soem apresentar em maior ou menor grau. Dessa maneira: tornam-se, via de regra, mais permeáveis e cooperantes na reestruturação da personalidade em bases novas e mais promissoras.

Caso 1 - P. A. P., branco, brasileiro, casado, com 45 anos de idade comerciànte. Iniciou sua vida profissional como motorista de caminhão. Numa situação de emergência, por conhecer datilografia, passou a trabalhar em escritório. Mau grado pequena instrução e mercê de grande inteligência e senso de organização, tornou-se, em pouco tempo, chefe do escritório, com dois empregados soh suas ordens. Devido ao rápido desenvolvimento da firma, viu-se com cinco auxiliares, entre os quais um contador formado. Em breve, as relaçōes entre êle e èsses novos elementos tornaram-se tensas, pois èstes alegavam, aos diretores da emprêsa, que o paciente não tinha competência para dirigir um escritório de tal envergadura. Nesse estado tensional viveu cêrca de quatro anos, até que, cansado, resolveu pedir demissão do cargo, indo estabciecer-se com um pequeno empório em sua cidade natal. Com sua saída, a ordein e organização do escritório começaram a decair, pelo que os diretores o convidaram para voltar ao emprêgo. Apesar de apreensivo, reassumiu o cargo. Nos poucos dias em que permaneceu no escritório a fim de tomar contcto com o serviço, percebeu que não era capaz de dominar a situação e implantar sua antiga autoridade. Mas não podia voltat ätrás, por ter liqüidado seu pequeno estabelecimento comercial no interior. Durante a viagem que fêz para ir buscar a família e seus móveis na eidade onde 
vivia, deflagrou-se a reação parafrênica, nìtidamente psicógena. Eis como o próprio paciente descreveu êsse episódio agudo: "Dirigi-me para a estação para carimbar minha passagem e tomei o trem correndo, porque já estava na última hora. Imediatamente comecei a sentir-me perseguido e fiquei com muito mêdo. Pedi uma garrafa de cerveja, mais para me armar com a garrafa, que para beber cerveja. Tomei um pequeno gole da bebida e comecei a ter ânsias de vômito e então tive a impressão de que estava envenenado. Apavorado, comecei a procurar alguma pessoa conhecida e encontrei a senhora do A. C., a quem pedi socorro, pois estava alucinado de mêdo. A minha impressão era tão aparente de verdadeira, que cheguei a vomitar três vezes".

Chegou a seu destino em franco surto psicótico. Por êsse motivo, ao cabo de poucos dias, voltou a S. Paulo a fim de ser internado. Dêmos, novamente, a palavra ao paciente: "Quando tomamos o automóvel com destino a São Paulo, a minha intenção era procurar o Delegado Regional, para me queixar de perseguido, mas logo que cheguei vi que tinha sido internado e, dêsse momento em diante, aceitei o fato e me sujeitei ao tratamento médico prescrito, que consistiu em 10 cletrochoques e em 20 comas pela insulina, do que obtive ótimos resultados, pois cngordei 10 quilos".

Internado, dizia haver um "complot" contra êle, chefiado por X., que conseguira reunir os "tiras" da polícia da Capital para liquidá-lo na primeira ocasião favorável. Quando the perguntávamos como conseguira saber da organização dêsse "complot", ria-se sarcàsticamente, respondendo que nós sabíamos úisso tão bem como èle. Acrescentava que todos os dias, principalmente à noitinha, vozes ameaçadoras anunciavam seu próximo fim. Um dia, chamou-nos a atenção para um enfermeiro que estava com gravata vermelha; isso queria dizer que era espião a soldo de $\mathrm{X}$. e estava encarregado de dar o sinal para um ataque coletivo à sua pessoa. Relutava em sair do quarto, pois via entre os enfermeiros e outros pensionistas, "tiras" disfarçados e hostis a sua pessoa. Até gôsto e cheiro esquisito na comida estava começando a sentir, quando iniciamos o tratamento que o observado descreveu. Com isso desapareceu o delírio de matiz francamente persecutório, continuando, no entanto, a demonstrar certo comprometimento do juízo crítico, pois achava sua moléstia sem importância, julgando só necessitar voltar imediatamente ao serviço. Demos-lhe, então, uma assistência psicoterápica contínua e prolongada, revendo sua vida desde tempos remotos e mostrando-lhe, aos poucos, a gênese do surto psicótico que o havia acometido, aconselhando-o a procurar um mistér de acôrdo com suas possibilidades inteletuais e culturais, pois do contrário iria submeter-se novamente a uma situação insustentável. Certa manhã encontrâmo-lo, felizmente, fora daquela impassibilidade, daquela indiferença que vinha demonstrando; estava com os olhos avermelhados de tanto chorar, pois compreendera afinal sua situação. Seguiu nosso conselho, empregando-se inicialmente em uma fábrica, onde exerceu função que não demandava grandes conhecimentos técnicos, nem exagerado esfórço mental. Aí permaneceu cêrca de dois anos, voltando em seguida para sua terra natal, onde estabeleceu-se novamente com um pequeno armazem de sêcos e molhados, ganhando o necessário para o sustento dos seus.

Caso 2 - C. B. W. branca, casada, com 39 anos de idade. Nenhum antecedente pessoal ou hereditário merece ser assinalado. Dois mêses antes de ser internada, ao atender a um chamado telefônico, ouviu uma voz lhe dizer: "Vem, siga-me". Largou imediatamente o fone, desceu a escada e, no andar térreo, seu clhar foi dirigido, por fôrça estranha, para uma gaiola onde havia dois passarinhos: A voz disse-lhe, novamente: "Você está prêsa como um pássaro; obedeça-me, que eu farei você ficar livre". Continuou sua vida rotineira, apesar de ouvir a voz que insinuava: "Você não deve ter amor pelo seu marido 
mmo esposo e sim como simples amigo e assim serão mais felizes". Nunca essas vozes disseram-lhe cousas desagradáveis. Em seguidla, começou a ter sensação de que uma cousa estranha dentro de seu corpo, por vezes, lhe dirigia os movimentos, independentemente de sua vontade. Em certas ocasiões, as vozes, que pareciam nascer dentro dela, diziam-lhe que devia abandonar a casa, ainda que temporàriamente, pois ela tinha que cumprir missão determinada por Deus. Perguntada se é feliz junto a seu marido, 22 anos mais velho que ela, responde ser êle muito bom e compreensivo; fica ruborizada e acrescenta nada the faltar para ser feliz. Fora do tema delirante, apresenta-se lúcida, bem orientada, com hoa comprensão dos fatos de crdem geral. Uma vez internada. as vozes continuavam insinuando-lhe que, se abandonasse o marido, seria completamente feliz. A paciente narra ter sido educada com muito rigor pelo pai, homem voluntarioso e intransigente, plasmando assim sua mentalidade e caráter numa atmosfera em que a submissão total era a melhor fórmula de adaptação. Assim, as manifestações da vontade e desejos próprios da criança, da adolescente e da moça que tinha muitas ilusões, eram necessàriamente recalcados. Casou-se com um homem quc. apesar de bom e compreensivo, era muito mais velho que ela (substituto e continuador do pai). As vozes, refletindo o estado de conflito interior da paciente, contradiziam-se por vezes, alternando os conselhos de liberdade - ainda estava em tempo de gozar a vida em toda sua plenitude - com outros de adaptação — seria feliz querendo o marido como um bom amigo. Mulher honesta. mas com necessidades sexuais - embora o negasse, dizendo que essas questões pouco a preocupavam - não é de admirar que a reação parafrênica fôsse a tradutora dessa confusão de sentimentos.

Tendo-se mostrado impermeável à psicoterapia, pois mantinha-se em atitude de franca resistência, afirmando que seu marido era muito bom, que nada lhe faltava, fizemos quatro aplicações de eletrochoque. As alucinações se esmaeceram, bem como as idéias delirantes delas decorrentes. Continuava, no entanto, demonstrando resistência quanto a investigações no sentido de seus sentimentos mais íntimos, caindo em grande emotividade quando insistíamos nesse ponto. Fizemos, por isso, várias sessões de narcoanálise pelo tionembutal. $\mathrm{Na}$ terceira, relatou, com muita emotividade, que havia um jovem que a vinha preocupando sèriamente, embora nada tivesse havido de íntimo entre os dois. Fizemos, então, sob narcose, a racionalização de seu caso, procurando dar-lhe os elementos para a sublimação, baseados na existência de um filho. Adveio sensação de maior segurança interna e externa, tornou-se menos emotiva, conseguindo ter alta em dezembro do ano passado em perfeitas condições psicossomáticas, estado em que ainda perınanece.

Caso 3 - P. L., branca, brasileira, solteira, sem antecedentes psicopáticos. Esta paciente, que tivemos ocasião de examinar há cêrca de 10 anos apresentava grave cardiopatia, da qual faleceu, o que nos impediu tentar qualquer terapêutica de choque. Não conseguimos, assim, "amaciar" a doente, tendo redundado inútil tôda tentativa para uma psicoterapia eficiente. Não se tendo casado, mostrava-se aparentemente conformada com a incômoda posição de "solteirona" até que, com o falecimento de seus progenitores, viu-se sòzinha no mundo e sem recursos financeiros que a pusessem ao abrigo das necessidades. Nessas circunstâncias, foi obrigada a aceitar atuxílio financeiro de um irmão que, para isso, tinha que fazer ingentes sacrifícios. Tal situacão passou a ser extremamente penosa, a ponto de provocar o aparecimento de fenómenos de automatismo mental (Clérembault): estranheza de pessoas e cousas, paradas e vazios do pensamento, crises de ideorréia, dúvidas súbitas, perplexidades, aprocexias transitórias. Em seguida, começou at cuvir vozes, entre as quais a do "Aguiar", certamente substituto ider "principe encantado", que the dizia cousas agradáveis e lisonjeiras. Tempos depois, houve interferência "dela", voz provàvelmente simbólica de alguma rival 
detestada, que passou a interferir no romance delirante, com frases insultuosas, no intuito de a desmerecer diante do "Aguiar". Fora disso, mostrava-se lúcida, perfeitamente orientada, ventilando os assuntos de ordem geral com bastante acêrto. Nossa observada era, no início, mansa, cordata e comunicativa; aos poucos, foi-se tornando irritadiça, belicosa, revoltada, chegando, pouco antes de entrar em assistolia jrreversível, a voltar sua hostilidade contra as enfermeiras e outras pensionistas do pavilhão em que se achava.

Este caso demonstra que as reações parafrênicas psicogenéticas, ou parafrenoses, cmbora de melhor prognóstico que as parafrenias de fundo orgânico, onde êle é sempre reservado, têm tendência a cristalizar-se, se o especialista não intervier com rapidez, energia e eficiência, lançando mão de todos os recursos terapêuticos de que pode dispor na atualidade.

Rua Arnaldo, 25 (Itaim) - S. Paulo 